Etnográfica

Revista do Centro em Rede de Investigação em

Antropologia

vol. $23(2) \mid 2019$

Vol. 23 (2)

\title{
La carpeta de Simone: objetos, género y extranjería en la experiencia carcelaria
}

Simone's folder: objects, gender and foreign status in prison experience

\section{María Ruiz Torrado}

\section{(2) OpenEdition}

Journals

Edición electrónica

URL: https://journals.openedition.org/etnografica/6674

DOI: 10.4000/etnografica.6674

ISSN: 2182-2891

\section{Editor}

Centro em Rede de Investigação em Antropologia

\section{Edición impresa}

Fecha de publicación: 1 junio 2019

Paginación: 275-298

ISSN: 0873-6561

\section{Referencia electrónica}

María Ruiz Torrado, «La carpeta de Simone: objetos, género y extranjería en la experiencia carcelaria», Etnográfica [En línea], vol. 23 (2) | 2019, Publicado el 24 junio 2019, consultado el 19 enero 2022. URL: http://journals.openedition.org/etnografica/6674 ; DOI: https://doi.org/10.4000/etnografica.6674

\section{(c) (7) (8)}

Etnográfica is licensed under a Creative Commons Attribution-NonCommercial 4.0 International License. 


\section{La carpeta de Simone: objetos, género y extranjería en la experiencia carcelaria}

\section{María Ruiz Torrado}

Tomando como eje una carpeta compuesta de 129 documentos penitenciarios guardados por una mujer a la que he llamado Simone, este artículo pretende profundizar en el significado del encarcelamiento para las mujeres extranjeras recluidas en el País Vasco. Mediante un caso concreto e ilustrativo, y a partir de aportaciones antropológicas feministas y relativas a la cultura material, se abordan tres aspectos: (i) las interacciones entre sujeto y objeto; (ii) las desigualdades de género, clase social y etnia/raza en el sistema penitenciario; (iii) la agencia y las prácticas de resistencia cotidianas para mitigar los efectos del encierro.

PALABRAS-CLAVE: mujeres presas, encarcelamiento, relaciones sujeto-objeto, género, extranjería.

Simone's folder: objects, gender and foreign status in prison experience - A folder consisting of 129 prison documents kept by a woman I named Simone is the central topic of the current paper, which seeks to delve into the meaning of imprisonment for foreign women imprisoned in the Basque Country. Through a specific and illustrative case, and using feminist anthropological contributions and proposals about material culture, three topics will be addressed: (i) interactions between the subject and the object; (ii) inequalities related to gender, social class and ethic group/race; (iii) agency and daily resistance techniques to reduce the effects of imprisonment.

KEYWORDS: women inmates, imprisonment, subject-object relationships, gender, foreign status.

RUIZ TORRADO, María (maria.ruizt@ehu.eus) - Grupo de Investigación AFIT, Departamento de Filosofía de los Valores y Antropología Social, Universidad del País Vasco (UPV/EHU), País Vasco, España. 


\section{INTRODUCCIÓN}

La primera vez que vi la carpeta de Simone nos encontrábamos las dos solas en el salón de su casa, compartiendo una tranquila y agradable sobremesa, tras haber disfrutado de una deliciosa comida preparada por ella. ${ }^{1}$ Era a principios del mes de marzo de 2014. Hasta aquel momento, Simone nunca había hecho mención de esa carpeta. No obstante, hacía ya varios años que nos conocíamos y habíamos mantenido muchas conversaciones, formales e informales, sobre las vivencias documentadas en su archivador. Nos habían presentado a mediados de septiembre de 2011, en la casa de acogida de una asociación religiosa, en el contexto de un estudio antropológico sobre género y prisión. ${ }^{2}$ Por aquel entonces, Simone residía en esa casa, junto con varios hombres y mujeres que, al igual que ella, habían estado encarcelados. Simone se había acogido al programa de "integración social" de la asociación, al ser esa su única opción para poder salir del encierro penitenciario antes de completar su condena. Estaba en régimen abierto, a la espera de libertad condicional, y cada quince días debía presentarse en el centro penitenciario para "firmar". Yo, en cambio, había acudido a la casa con una compañera de investigación, dispuesta a entrevistar a una mujer ex-presa, con el propósito de llevar a cabo la primera de una serie de entrevistas en profundidad. Esa primera entrevistada resultó ser Simone y, así, en el tiempo que pasamos juntas, nos relató sus experiencias en prisión, visiblemente afectada casi en todo momento. Magnífica narradora, con una gran capacidad para expresar mediante palabras sus emociones y dotada de una sensibilidad especial, nos hizo adentrarnos en su valioso testimonio, muy rico en matices. Conectamos bien y nos despidió con un fuerte abrazo. Pero, aunque en ese momento no lo sabíamos, en realidad no fue una despedida, sino el comienzo de una relación de amistad que continúa en la actualidad.

El día en que Simone me mostró por primera vez su carpeta habíamos quedado para comer juntas en su casa. El tema de la cárcel surgió de improviso en la conversación, como en muchas otras ocasiones, al ser parte de su experiencia vital y estar yo inmersa en la realización de una tesis doctoral sobre mujeres encarceladas. ${ }^{3}$ En un momento dado, ella se levantó de su asiento

l Este artículo se ha elaborado con una Ayuda para la Contratación de Doctores Recientes hasta su Integración en Programas de Formación Postdoctoral de la Universidad del País Vasco (UPV/EHU). Quiero agradecer a Simone su generosidad al prestarme la carpeta con su documentación penitenciaria, así como su atenta lectura de este artículo. Asimismo, quiero mostrar mi agradecimiento a la profesora Mari Luz Esteban, por sus comentarios, sugerencias y críticas constructivas. Para mantener el anonimato de la protagonista y las personas citadas por ella, en todo momento utilizaré nombres ficticios.

2 La investigación "Mujeres ex-presas: vulnerabilidad y autonomía", por Miren Arbelaitz, Edurne Bengoetxea, Alma Méijome, María Ruiz, y Laura Vara (beca de investigación Emakunde - Instituto Vasco de la Mujer - para la Igualdad entre Mujeres y Hombres, 201 1).

3 Llevé a cabo mi tesis doctoral bajo la dirección de Mari Luz Esteban en la Universidad del País Vasco (UPV/EHU), con una beca predoctoral del Gobierno Vasco (2013-2016). Asimismo, para [continua] 
y se dirigió a su dormitorio, regresando a los pocos minutos con una carpeta en las manos. Volvió a sentarse a mi lado y abrió el archivador. La única explicación que me dio sobre toda la documentación ahí guardada fue que había ido recopilando y almacenando todos los documentos relativos a su paso por la prisión de Martutene (País Vasco). ${ }^{4}$ Había muchísimos escritos, de muy diversa índole, pero unos pequeños post-it azules fueron los que captaron su atención. Comenzó a leerlos y a traducírmelos del portugués brasileño al español, explicándome que en esos pequeños papelitos había escrito lo que deseaba decirle a su hermana al ingresar en prisión, pese a no ser capaz de hacerlo, por la vergüenza y el sentimiento de culpabilidad que le generaba su situación. Al cabo de unos días, muy impactada todavía por el escrito de Simone, le planteé la posibilidad de utilizar ese material en mi tesis doctoral, que trataba sobre las desigualdades de género, las prácticas de resistencia cotidianas y la agencia de las mujeres encarceladas en el País Vasco. ${ }^{5}$ Ella accedió muy generosamente.

En este artículo, escrito varios años después de las escenas descritas, pretendo retomar la carpeta de Simone para abordar las interacciones entre sujeto y objeto, y analizar el contenido de todos los documentos guardados - documentos que en su día no examiné, ni siquiera hojeé -. Así, utilizando la carpeta de Simone como eje, convirtiendo sus numerosos y diversos archivos en hilo conductor, profundizaré en el significado del encarcelamiento para una mujer de origen extranjero en el País Vasco. A través de un único caso, concreto e ilustrativo, intentaré reflejar las desigualdades de género, clase social y etnia/ raza presentes en el sistema penitenciario, así como la agencia y algunas de las prácticas de resistencia que las mujeres encarceladas llevan a cabo para mitigar los efectos del encarcelamiento y hacer la reclusión un poco más llevadera o soportable. Para ello, recurriré a las aportaciones de la antropología feminista (Thurén 1993; Méndez 2008) y de la antropología de los objetos (Alonso Rey 2012, 2016, 2017).

su realización, hice una estancia de tres meses en el Centro em Rede de Investigação em Antropologia (CRIA), bajo la supervisión de Manuela Ivone Cunha. La investigación fue defendida el día 20/12/2016. 4 La cárcel de Martutene se encuentra en Donostia-San Sebastián, en el País Vasco. De estructura radial y pequeño tamaño, tiene un único departamento de mujeres, provisto de 11 celdas. Alberga a unas 30 mujeres presas.

5 Las prácticas de resistencia cotidianas y la agencia de las mujeres presas no son temas que por lo general se hayan tratado demasiado. Las escasas investigaciones realizadas hasta hoy (Bhavnani y Davis 2007 [1996]; Makowski 1997; Bosworth 1999; Ribas, Almeda y Bodelón 2005; Mageehon 2008; Fili 2013) han defendido que las mujeres reclusas siempre cuentan con cierta capacidad de acción y transformación de las relaciones de poder, al ser la resistencia una posibilidad que existe incluso en los marcos más restrictivos. Según esos trabajos, la prisión es un ámbito evidente de discriminación, desventaja y vulnerabilidad para las mujeres presas, pero el poder penitenciario nunca resulta ni total ni absoluto y las mujeres encarceladas en ningún caso dejan de ser agentes o sujetos activos. La citada tesis doctoral partió de dichos planteamientos. 
Simone nació en una gran ciudad brasileña en el año 1977. Ella explica que en su país llevaba una vida "normal y corriente". Estudiaba y trabajaba, tenía un grupo de amistades amplio y unos lazos familiares fuertes y estables. Sin embargo, con la intención de dejar atrás algunas malas noticias que habían trastocado un poco su vida, así como por conocer otros contextos culturales, en 2006 emigró al País Vasco, aprovechando que tenía un contacto allí. A los pocos meses de llegar, para ganar dinero, comenzó a trabajar limpiando un club de prostitución. Allí vivió dos redadas de la Policía Nacional española. En la primera redada, la detuvieron por encontrarse en situación irregular, sin permiso de residencia ni trabajo; pero le dieron una carta de expulsión y la dejaron libre. En la segunda, en cambio, fue detenida, porque una compañera del club guardó unas bolsitas de cocaína en la mochila de Simone y fueron encontradas por la Policía. Tras pasar tres días en un calabozo, la dejaron en libertad a la espera de un juicio, que se realizó a los dos años. Acusada de un delito contra la salud pública, fue condenada a una pena de cuatro años de prisión. La jueza, no obstante, en lugar de esa condena, ordenó que Simone fuera expulsada del Estado español. ${ }^{6}$ Pero ella decidió no marcharse, porque le parecía vergonzoso tener que regresar de esa forma, no habiendo cometido el delito del que le acusaban. En ningún momento estuvo del todo tranquila con ese asunto, aunque tampoco llegó a imaginarse en prisión. El l de septiembre de 2009, estando en otra ciudad con un nuevo empleo como cuidadora interna, la Ertzaintza (Policía Autonómica del País Vasco) la detuvo y la encarceló en la prisión de Martutene por incumplimiento de la sentencia.

La carpeta de Simone, que contiene documentos desde el día que entró en prisión hasta el día en que logró el tercer grado (régimen abierto), es de cartón azul, con acabado mate y tamaño folio (figura 1). Podría decirse que es una de esas carpetas "típicas" y "de toda la vida”, que van más allá de las modas pasajeras. En su exterior no tiene ninguna inscripción, apunte o anotación sobre lo que hay dentro. Pero al abrirla, al tiempo que se percibe el característico olor del papel, se descubren 129 documentos penitenciarios de muy diversa índole, guardados sin ningún orden. Hay documentos originales y fotocopias, escritos a mano, ordenador o máquina; páginas sueltas, grapadas, unidas con clips... La mayoría son documentos judiciales y oficiales del centro penitenciario, pero también hay otro tipo de documentación, como los mencionados post-it.

6 Según el artículo 89 del Código Penal, si se condena con una pena de no más de seis años a una persona inmigrante que no tiene permiso de residir en el Estado español, es posible sustituir la pena por expulsión del territorio, así como aplicar una prohibición de volver a cualquier país de la zona Schengen en un plazo de tres a diez años. En el actual contexto penal, las sustituciones de la pena por expulsión han ido en aumento. 
Al observar a Simone con su carpeta, es posible apreciar una relación de gran intensidad y carga emocional. Muestra de ello es que cuando le propuse la posibilidad de utilizar su carpeta para este artículo, pese a mostrarse tan colaborativa y generosa como siempre, pude percibir que mi proposición la había removido profundamente, al referirse al episodio más doloroso de su vida. No obstante, cuando a los días quedamos para conversar sobre la carpeta y hojear los documentos, estaba tranquila y segura. Cuando llegué al lugar en el que habíamos quedado, ella estaba de pie ante una mesa, con la carpeta abierta, repasando su contenido. Enseguida empezó a contarme detalles sobre la docu-

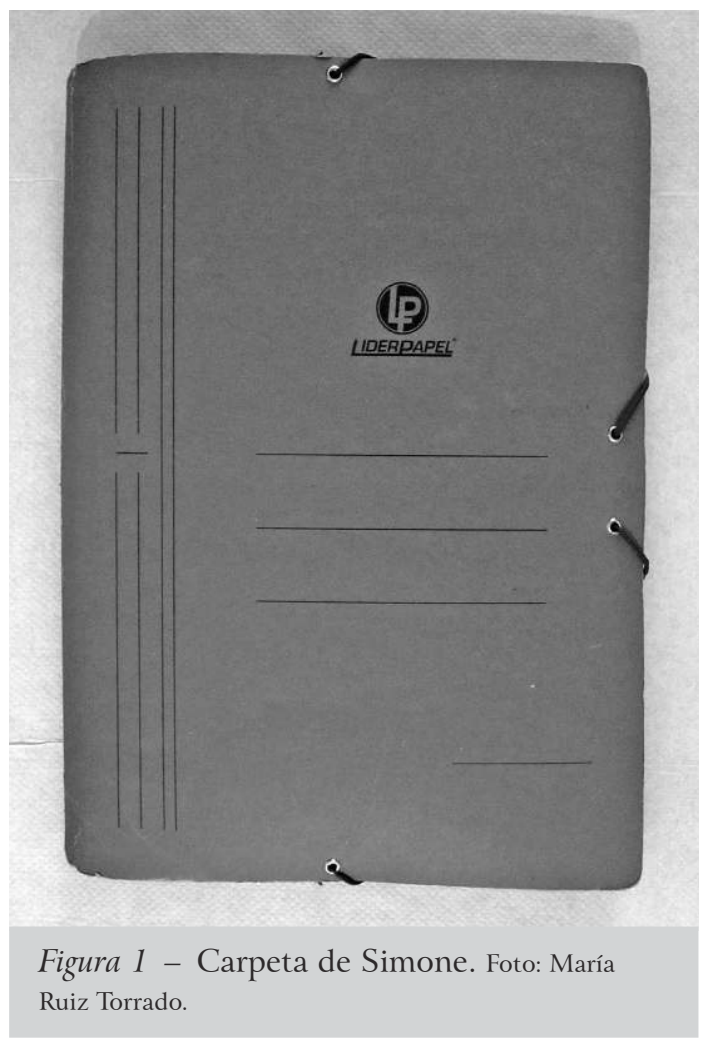
mentación guardada y su paso por prisión. De alguna manera, el contenido de la carpeta la conectó con toda esa parte de su biografía. Examinó cada una de las páginas allí presentes, explicándomelas, dándome más detalles y contándome historias que nunca antes me había relatado. Habló sobre prisión, casi sin pausa, y destacó el valor de sus documentos, ya que apenas nadie tiene guardados archivos de ese tipo. Cuando más adelante volvimos a quedar para aclarar algunas de mis dudas, sin embargo, las malas sensaciones transmitidas por la carpeta volvieron a aflorar. $\mathrm{Su}$ voz sonaba temblorosa y entrecortada. Estaba más callada y pensativa, y hacía más pausas al hablar.

Precisamente, desde ese punto de vista de las emociones, la antropóloga Natalia Alonso Rey $(2012,2016,2017)$ ha defendido el análisis de los efectos y los afectos que los objetos son capaces de producir - a menudo, inesperadamente - en los sujetos. Según esta autora, es importante abordar lo que los objetos pueden "hacer" y, para ello, es necesario profundizar no solo en las narraciones que surgen en los encuentros entre objeto y sujeto, sino también en las emociones y en las intensidades - entendidas como capacidad de afectar y ser afectado - que se generan y que posteriormente pueden dar lugar a significados (Alonso Rey 2016: 43). El objeto no se explica sin el sujeto, pero el sujeto también necesita del objeto para explicarse a sí mismo, para contar 
su vida, para recrearla, así como para sentirla (Alonso Rey 2012: 54). Después de todo, las personas "hacen" a las cosas como las cosas "hacen" a las personas (Laviolette 2013, en Alonso Rey 2017: 27). Reflexiones similares sobre cultura material han dado lugar a diversos enfoques y aproximaciones teóricas sobre la agencia de los objetos o sobre una agencia compartida entre sujetos y objetos que se transforman mutuamente, campo en el que han destacado autores como Baudrillard (2010 [1968]), Wagner (1986), Miller (1987), Appadurai (1988), Latour (1993), Gell (1998), Strathern (1999), Henare, Holbraad y Wastell (2007) y Hicks (2010). Así, cuestionando las perspectivas más antropocéntricas, para las cuales los objetos no serían más que meras entidades sobre las que recae la intencionalidad humana, cada vez es más común reconocer que los objetos también son agentes, sujetos activos, actores sociales, parte constituyente - y no solamente reflejo o receptor - de los procesos sociales.

Según Alonso Rey (2016), las interacciones de las personas con sus objetos biográficos pueden ayudarnos a entender muchas de sus experiencias. Los objetos que las personas guardan son altamente significativos para sus poseedores, porque constan de un claro poder simbólico y evocativo, que remite a lugares, momentos y relaciones relevantes, dando lugar a continuidades dentro de las biografías (Alonso Rey 2012: 42). De ese modo, los objetos sirven para recordar y narrar el pasado, al funcionar como detonantes de rememoración de acontecimientos pasados. Pero su valía no queda ahí. Es importante tener claro que, si un objeto ha sido conservado a lo largo del tiempo, no ha sido por "aquello que fue", sino por "lo que es" en el presente - incluso por "lo que pueda ser" en el futuro -. El objeto remite al pasado, pero su importancia no acaba ahí. Su relevancia está en el presente, en cada una de las ocasiones en que sujeto y objeto se encuentran, actualizando las narraciones, reelaborando los significados, en un proceso dinámico e inacabado de gran intensidad emocional (Alonso Rey 2017: 288-289).

En el caso concreto de Simone, no es difícil apreciar la gran importancia que su carpeta tiene para ella. En su encarcelamiento, guardó y archivó prácticamente toda la documentación a la que tuvo acceso; y cuando llegó el día de dejar el centro penitenciario, no dudó en llevarse consigo la carpeta, camuflada entre apuntes de los estudios universitarios a distancia que realizó en prisión. Desde entonces, nunca se ha desprendido de la carpeta. Ha cambiado varias veces de residencia y la carpeta siempre la ha acompañado en los traslados. Estuvo con ella durante todo el tiempo que pasó en la casa de acogida, siguió con ella cuando se fue a vivir con la que fue su compañera de celda en prisión, y continúa con ella también en la actualidad, tras haberse ido a vivir con su pareja. El hecho de no haberse separado nunca de la carpeta indica su relevancia, al igual que lo hace también la forma en la que ha ido guardándola a lo largo del tiempo. Tanto en prisión como en el piso que compartía con su ex-compañera de celda, la carpeta estaba debajo del colchón de su cama, 
escondida, por motivos de "seguridad". En la actualidad, en cambio, la carpeta se encuentra dentro de una caja con la anotación manuscrita "Documentación Simone". En cualquier caso, la carpeta siempre ha tenido un lugar específico, no constantemente visible, recurriendo solo ocasionalmente a ella. Simone nunca ha podido - ni querido - prescindir de su carpeta, pero tampoco ha deseado tenerla permanentemente a la vista. En ese sentido, Alonso Rey (2012) señala que en el caso de los objetos que están guardados, lo más importante es saber que "están ahí", otorgarles un lugar y poder recordarlos, aunque no se recurra a ellos de manera habitual. Se tratarían de objetos casi invisibles, pero presentes en la memoria; objetos íntimos y privados, que no son para ser expuestos ni compartidos públicamente. Simone, por ejemplo, en todos estos años solo ha acudido esporádicamente a su carpeta, y raramente se la ha mostrado a otras personas. No obstante, siempre ha recordado perfectamente dónde estaba, así como lo que guardaba en su interior.

En cuanto al motivo de haber conservado la carpeta durante todo este tiempo, Simone me dio dos respuestas distintas. En la primera, contestó que había guardado la documentación por su situación de extranjera en situación irregular. Según expresó, el hecho de no contar con "papeles" y no tener cerca a su familia le hacía sentirse insignificante; como si no existiese del todo, como si fuera invisible, un fantasma, o sencillamente, nadie. Esa situación le hacía sentirse realmente vulnerable, pero encontró una forma de hacer frente a dicha sensación, recopilando y guardando su documentación penitenciaria en una carpeta. Al parecer, para ella ha sido y es una manera de materializar y reforzar su presencia; una forma de constar, obtener cierto arraigo, mostrar dónde ha estado y qué ha hecho. Por ello, también afirmó que puede que, si algún día obtiene el permiso de residencia, queme la carpeta. No obstante, ahora mismo, ese momento le parece tremendamente lejano. Es más, a día de hoy, a pesar de haber cumplido ya su condena, asegura que todavía se siente "presa", por la imposibilidad de dejar la situación de irregularidad, como consecuencia de tener antecedentes penales.

La segunda respuesta de Simone fue muy distinta. Simplemente, afirmó que no sabe por qué ha guardado la carpeta todos estos años, que no sabe explicar qué es lo que le ha llevado a actuar de esa manera. Según esta segunda contestación, Simone no tendría un relato explicativo de su comportamiento y el registro narrativo no serviría - o, por lo menos, no del todo - para dar sentido a su vínculo con la carpeta. Pero Simone planteó que quizás lo haya hecho porque no ha sido capaz de superar y "cerrar" la etapa de su vida correspondiente con su encarcelamiento. Al fin y al cabo, la carpeta evoca y materializa su paso por prisión. La conecta emocionalmente con la cárcel; con ese espacio, con ese tiempo, con las personas con las que se relacionó. Desde este punto de vista, Simone no sería capaz de desprenderse de la carpeta, de la misma manera que no podría despojarse de la experiencia carcelaria, al ser para ella una vivencia 
central; una vivencia que ha marcado su biografía profundamente, atravesando todo su ser.

Las dos respuestas dadas por Simone nos indican la relevancia que ese objeto posee para ella, además de reflejar el dinamismo característico de los encuentros entre sujeto y objeto - ya que, al reactualizar las narraciones y las emociones, emerge la posibilidad de que sus contenidos cambien -. La carpeta, en cualquier caso, es producto y productora de su vivencia en prisión.

\section{ESBOZO DE UN ENCARCELAMIENTO}

A través de la documentación recopilada en la carpeta de Simone, es posible conocer y trazar su paso por prisión. Hay archivos relativos a su entrada en el centro penitenciario de Martutene, así como referentes a su progresión de grado y excarcelación; archivos que, sin duda, proporcionan mucha información sobre su manera de valorar el sistema penitenciario en general y su vivencia carcelaria en particular.

Desde una perspectiva cronológica, el primer documento que descubrimos en la carpeta de Simone lo conforman los mencionados post-it azules (figura 2), ya que comenzó a escribirlos en su primer día en prisión, estando aún en el "módulo de ingresos". Según recuerda, el momento de entrar en la cárcel fue

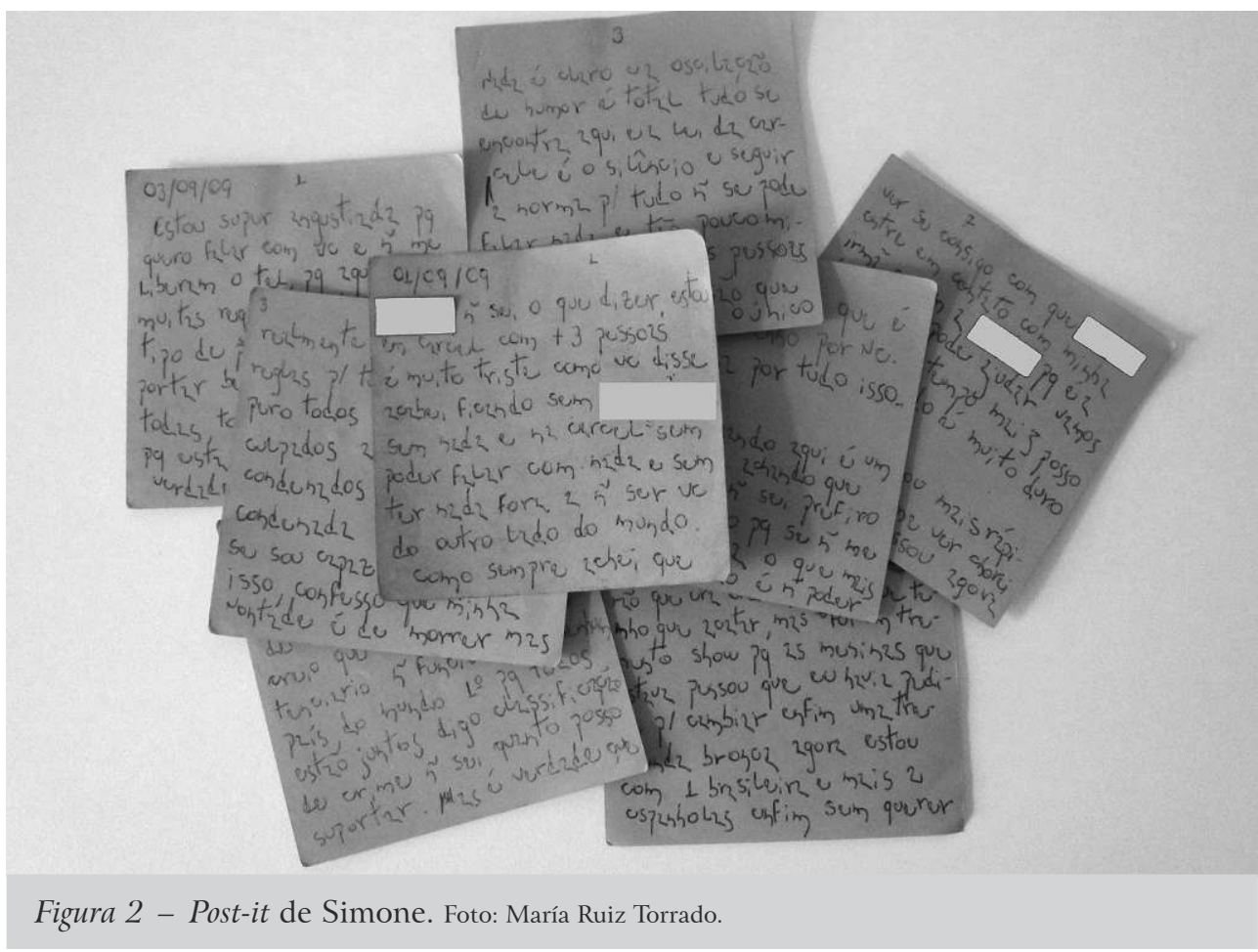


muy impactante y agobiante para ella. No entendía lo que ocurría, pero sentía asco y vergüenza de sí misma, al igual que soledad e indefensión por la situación que estaba viviendo. En esa tesitura, le dieron cinco minutos para llamar a su hermana en Brasil y comunicarle que estaba en prisión. No pudo volver a hablar con ella hasta pasada una semana. En ese intervalo de tiempo, escribió una especie de carta, algo parecido a un diario, en el que su hermana era la destinataria. Para ello, utilizó el único soporte que encontró en el módulo de ingresos: unos pequeños post-it. En ocho papelitos escritos por ambas caras y con letra minúscula, Simone reflejó lo que deseaba decirle a su hermana, pese a no atreverse realmente a hacerlo. Así plasmó sus sentimientos más profundos:

"[01/09/09] Karolina [hermana de Simone], ñ sei o que dizer estou em carcel $[\ldots]$ é muito triste como vc disse acabei ficando sem Joxepa [señora mayor que Simone atendía como cuidadora interna], sem nada e na carcel sem poder falar com nada e sem ter nada fora a ñ ser vc do outro lado do mundo. Como sempre achei que isso ñ fosse passar pq dentro de pouco estaria em casa contigo mas as coisas comigo ñ funcionam assim e estou aqui chorando com medo de tudo o que pode acontecer, Joxepa ñ sei como esta, minhas lágrimas já ñ tenho mais e estou morrendo de mido [...] ñ sei de verdade se sou capaz de suportar isso, confesso que minha vontade é de morrer mas ñ tem como, pq ñ tem como se matar aqui, o que mais desejo nesse momento é te abraçar bem forte mas a realidade é outra." ${ }^{7}$

“[02/09/09] Ka[rolina], tudo isso parece surreal [...] ñ sei quanto posso suportar. Mas é verdade que no fim acabei ficando sem nada e ñ sei quanto tempo vou demorar aqui mas ñ sei se tenho estrutura pra aguentar. Não tenho vontade de nada... E tudo é muito pesado."

"[03/09/09] Estou super angustiada pq quero falar com vc e ñ me liberam o tel [...] ñ tenho vontade de nada pq é tudo como uma pesadilha ou pior [...] assim declaro que tudo me faz longo e muito forte de passar. [...] vc aprende a valorar tudo mas o principal eu nunca deixei de valorar que é o amor que tenho por vc. E a vergonha por tudo isso."

“[04/09/09] O que estou usando aqui é um pouco de ilusão achando que vou sair pronto ñ sei prefiro acreditar nisso pq se ñ me morro cada dia o que mais me esta matando é ñ poder falar com minha irmã deve estar desesperada ñ sei o certo que vai acontecer só vou saber ao certo quando falar com a advogada $[\ldots]$ vamos ver quanto tempo mais posso aguentar tudo é muito duro." 
“[07/09/09] [...] vamos ver se consigo sair daqui o quanto antes a advogada volta de férias amanhã então acho que dentro de pouco consigo algo... cada vez te quero mais Karolina e quando sair daqui nos vemos e viveramos coisas novas, que saudade de vc..."

Como se puede apreciar, se trata de una narración intensa: escribe muy rápido y faltan signos de puntuación. De algún modo, parece una "urgencia narrativa" (Curcio 201 l), en la que se refleja su estado de ánimo. La escritura así - aunque sea de forma bastante inconsciente para Simone - emerge como práctica de resistencia ante el encarcelamiento; en concreto, como forma de expresión o vía para poder contarle a Karolina todo lo que quiere decirle y no puede, porque le resulta doloroso. Escribir lo que siente en el papel le ayuda a superar las dificultades de comunicación. Le vale para gestionar su sufrimiento, dar nombre a lo que siente y expresarlo, además de para producir una presencia simbólica y acercar a su hermana. Después de todo, debemos tener en cuenta que la escritura - entendida en sentido amplio - siempre ha sido muy importante en el contexto penitenciario, fundamentalmente por dos motivos: uno, porque supone una práctica comunicativa de profundo contenido identitario - en una situación en la que, justamente, ciertos aspectos identitarios y comunicativos se encuentran muy mermados - (Gándara 2005); y el otro, porque a través de la escritura las personas presas pueden intentar materializar su voz y obtener un reconocimiento negado por la sociedad (Retolaza 2014).

En el caso de Simone, se percibe ese deseo de lograr legitimidad social y convertirse en interlocutora válida; ya que pese a haber tenido siempre el apoyo de su familia, ella temía haber roto su confianza y que no la respetasen más. Sin duda, experimentaba los efectos del estigma de las mujeres encarceladas. Al fin y al cabo, las actitudes sancionadoras y criminalizadoras con ellas son habituales (Davis y Faith 2002), como si el hecho de ser mujer fuera un agravante. Sus transgresiones son evaluadas en términos morales y sufren mayor reproche social, al entenderse que han vulnerado tanto las leyes oficiales, como las normas sociales y los mandatos de género. Para el imaginario colectivo, cometer un delito e ingresar en prisión es irreconciliable con ser una "mujer de verdad" o una "mujer como es debido", por considerarse incompatible con el modelo de feminidad hegemónico (Naredo 2007; Juliano 201 l). Así, más allá de transmitir que todas las personas presas son malas, se difunde la idea de que, si son mujeres, posiblemente también sean malas madres, hijas y esposas, además de ciudadanas irrespetuosas y poco responsables (Faith 2011 [1993]; Almeda 2010). Esas visiones hacen que ellas tengan que sufrir un mayor estigma, no solo como delincuentes, sino como "mujeres delincuentes" (Herrera Moreno 1993, en Naredo 2007: 27 1); lo que se traduce en negación de respeto, desvalorización y menosprecio (Goffman 2006 [1963]; Juliano 2004). Igualmente, 
es de destacar que los efectos de la propia interiorización de los modelos de género dominantes son devastadores, ya que la mayoría de las mujeres encarceladas viven con mucha preocupación y angustia la situación de las personas que "dejan" fuera, sintiéndose culpables y avergonzadas, por haberles "abandonado" y hacerles sufrir (Juliano 2009: 89-90). En el caso de Simone podemos constatar dichas apreciaciones, pues tanto la vergüenza como la culpa hacia su familia estuvieron muy presentes durante su encarcelamiento - incluso tras su salida de prisión -.

Más allá de los post-it de Simone, en su carpeta destacan igualmente varios documentos sobre su progresión de grado penitenciario. Echándoles un vistazo rápido, es posible apreciar el androcentrismo característico del sistema penitenciario (Almeda 2003), ya que en la mayoría se hace mención al "penado" o "interno", a pesar de estar refiriéndose a Simone. Así pues, parecen archivos elaborados mecánicamente, utilizando un mismo esquema - masculino genérico - para toda la población reclusa, limitándose a modificar el nombre de la persona presa y la fecha del documento. Llevando a cabo una lectura más pausada de esos mismos archivos, sabemos que, al mes de ser encarcelada, la Junta de Tratamiento del centro penitenciario decidió la clasificación de Simone en segundo grado (régimen ordinario), porque "de su valoración se infiere que en el penado concurren circunstancias personales y penitenciarias de normal convivencia, sin que pueda afirmarse que está capacitado, por el momento, para llevar un régimen de vida en semi-libertad". Asimismo, descubrimos que la Junta de Tratamiento propuso que fuera trasladada al centro penitenciario de León - aunque finalmente ese traslado no llegara a realizarse - y que su primer permiso ordinario fue al año y los tres meses de ingresar en prisión. La documentación también nos muestra que sus permisos de salida tuvieron una duración cada vez mayor, pero el centro penitenciario mantuvo siempre las mismas condiciones: por una parte, presentarse ante la Policía al inicio y al final de cada permiso; y, por otra, estar bajo la tutela de una asociación de acogida. Al año y medio de su encarcelamiento, comenzó su incorporación progresiva al "medio abierto", logrando rápidamente el tercer grado.

El sistema de grados o el sistema progresivo ha sido descrito como un mecanismo para reforzar la capacidad disciplinaria y el control de la institución penitenciaria sobre las personas reclusas (Foucault 2012 [1975]). Sin duda, como más adelante comprobaremos, ha sido algo que afectó profundamente a Simone. Pero, aun con todo, los documentos de su carpeta nos enseñan que se rebeló contra varias de las decisiones de la Junta de Tratamiento; sobre todo, mediante recursos enviados al Juzgado de Vigilancia Penitenciaria de Bilbao (País Vasco). Las quejas de Simone nos permiten ver su agencia; es decir, su capacidad de interactuar en el terreno y llevar a cabo prácticas deliberadas - más o menos conscientes - orientadas a la consecución de sus intereses o deseos, transformando las situaciones y las relaciones sociales, dentro de ciertas 
condiciones de posibilidad (Ortner 2006). ${ }^{8}$ No obstante, sus recursos también nos posibilitan apreciar algunas de las desventajas que sufren las mujeres encarceladas de origen extranjero. Al fin y al cabo, entre la documentación de Simone, hallamos recursos de queja en contra de ser trasladada a otro centro penitenciario, así como en contra de denegarle el tercer grado y mantenerla en régimen ordinario. Precisamente, las autoras que han abordado la situación de especial vulnerabilidad que viven las presas extranjeras (Ribas, Almeda y Bodelón 2005; Imaz y Martín-Palomo 2007) han señalado que suelen ser trasladadas de una prisión a otra según las conveniencias del sistema penitenciario y que suelen pasar más tiempo de encierro, por sus dificultades para cumplir con los requisitos personales, residenciales y/o laborales demandados por la Junta de Tratamiento. Como consecuencia de considerarse que no tienen "arraigo", a muchas - sobre todo, a las que están en situación irregular - no les queda más remedio que tratar de conseguir el amparo de una asociación (Ribas, Almeda y Bodelón 2005: 118-119). Ese fue justamente el caso de Simone, ya que al no tener ni permiso de residencia ni un entorno familiar cercano, solo pudo comenzar a salir de prisión bajo la tutela de una asociación de acogida.

Otra realidad que queda reflejada en los recursos de queja que Simone envió al Juzgado de Vigilancia Penitenciaria es el proceso de aprendizaje que acompaña a todo encarcelamiento. Cuando entró en prisión, desconocía por completo el funcionamiento del sistema penitenciario. Pero, poco a poco, aprendió a desenvolverse en el medio. Interiorizó un nuevo lenguaje, asimiló otras formas de hacer, aprendió a valerse de los argumentos propios de la institución carcelaria. Muestra de ello es que, para tratar de conseguir beneficios penitenciarios, en sus recursos habla sobre "arraigo", "reeducación y reinserción", "buen comportamiento", "actividades formativas y ocupacionales", etc. y cita constantemente artículos de la Ley Orgánica General Penitenciaria y el Reglamento Penitenciario. En su proceso de aprendizaje, el personal penitenciario y las y los profesionales del derecho con los que Simone estuvo en contacto fueron fundamentales; tal y como reflejan los recortes de papel con apuntes manuscritos que varios profesionales del centro penitenciario hicieron para Simone (figura 3). Pero igualmente - o quizá más - importante fue lo aprendido junto al resto de mujeres encarceladas; especialmente, junto a su compañera de celda. Simone preparó varios recursos con su ayuda y orientación, y juntas estudiaron el Código Penal, tratando de obtener alguna rebaja

8 Profundizando algo más en su definición del concepto de "agencia", Ortner (2006) reflexiona sobre la capacidad de actuar de las y los sujetos abordando dos significados distintos: agencia en el sentido de poder y agencia en el sentido de (búsqueda de) proyectos. Según la autora, se trata de una distinción importante a la hora de abordar la resistencia, ya que puede ser entendida como agencia-poder que opera "por debajo" frente a la dominación - primer significado - o como agencia-proyecto de las personas subordinadas - segundo -. 


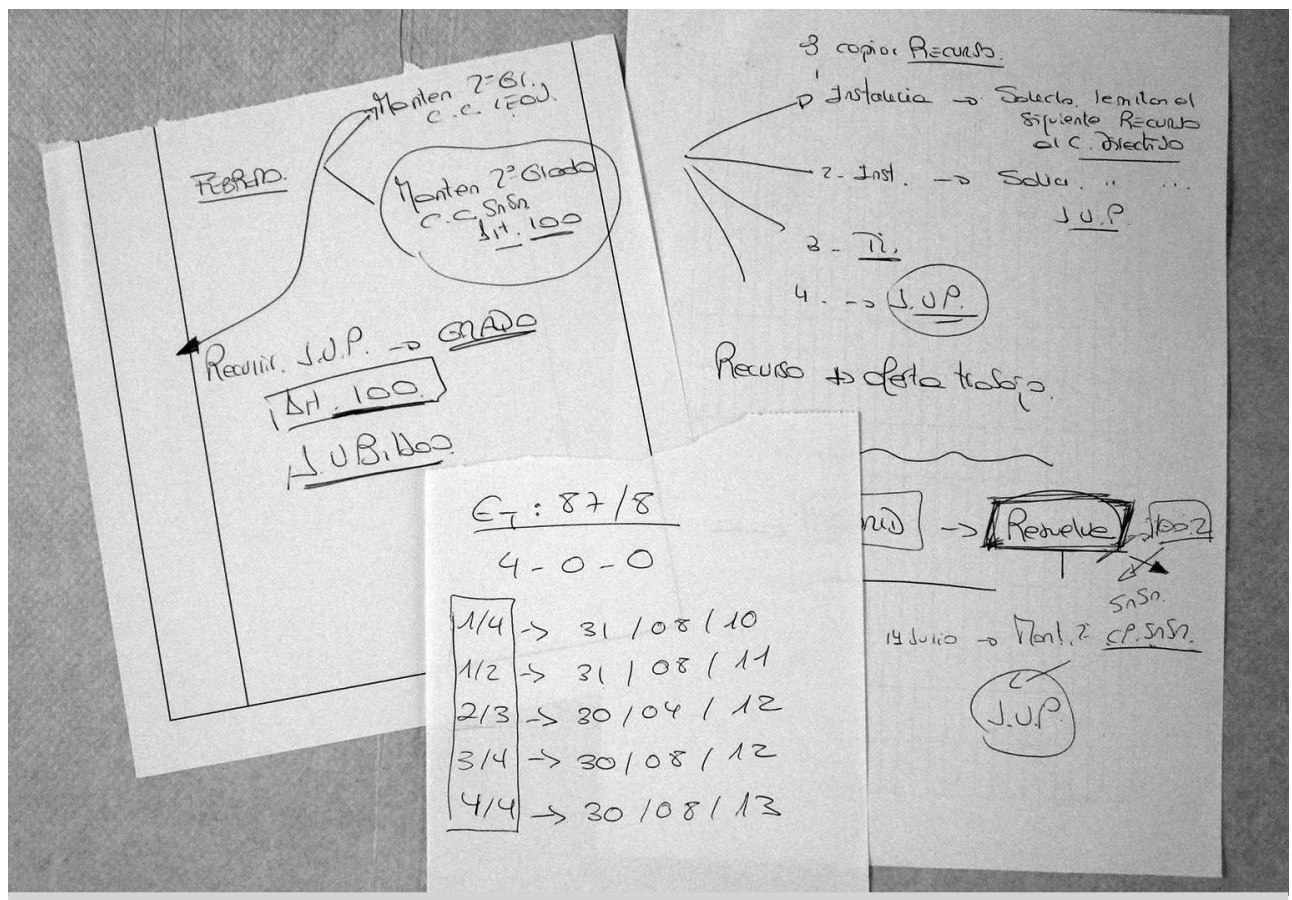

Figura 3 - Apuntes de profesionales penitenciarios. Foto: María Ruiz Torrado.

en sus condenas. Precisamente, eso indican varios documentos de la carpeta de Simone; en concreto, las fotocopias del Tratado de Traslados de Población Presa entre España y Brasil, así como las fotocopias de la reforma del artículo 368 del Código Penal, referente al tráfico de drogas ilegales (figura 4). Al igual que en el caso de Simone, la mayoría de las mujeres presas aprenden cómo actuar en prisión observando y recibiendo ayuda del resto de reclusas. Aunque la convivencia a veces sea algo tensa, se crean redes de protección mutua y solidaridad - tanto afectiva como material - (Bhavnani y Davis 2007 [1996]; Makowski 1997; Bosworth 1999; Ribas, Almeda y Bodelón 2005); relaciones de gran importancia, sobre todo, para quienes tienen poco o ningún apoyo cercano en el exterior, como era el caso de Simone.

Pese a sus múltiples intentos, Simone no consiguió ninguna reducción en su condena, ni tampoco salir de prisión antes de lo previsto; con lo que tuvo que seguir encerrada hasta que la Junta de Tratamiento y el Juzgado de Vigilancia Penitenciaria lo consideraron oportuno. Desde su perspectiva actual, haciendo balance del tiempo que pasó encarcelada, opina que la prisión es una de las peores experiencias por las que se puede pasar, porque allí se pierden la dignidad y la personalidad. Ella se sintió totalmente anulada e invalidada, como si habría dejado de ser parte de la sociedad. De hecho, le parecía que estaba en el lugar más bajo al que alguien puede llegar: 


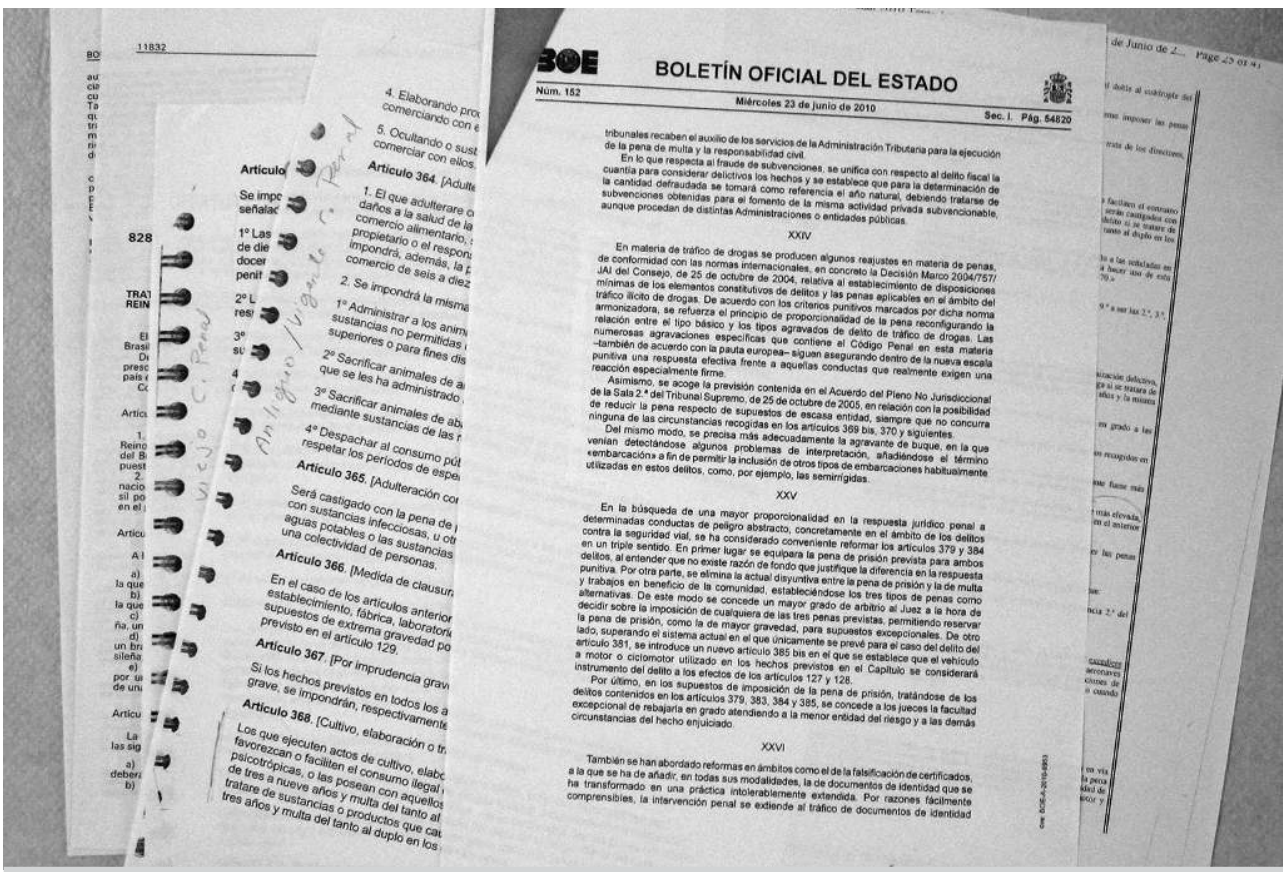

Figura 4 - Fotocopias sobre normativa penal y penitenciaria. Foto: María Ruiz Torrado.

"Un agujero... un agujero que parece que no va a tener... Un pozo, un pozo sin fondo, que todavía queda, queda, queda... No veo, no veo luz, no veo fondo, ino veo nada! Es un... agujero negro. La cárcel acaba contigo, acaba contigo... Te quita, te quita como persona... [...] Tú sientes que tú no eres parte de nada, de nada, tú no perteneces a nada... ni a la raza humana, porque es inclasificable".

Recordar su paso por prisión siempre es duro y doloroso para ella, porque las vivencias del encierro y la estigmatización la remueven en lo más hondo de su ser. No obstante, aunque le cueste, ha tomado la firme determinación de hablar en público, porque quiere hacer todo lo que esté en su mano para cambiar la situación actual. Desea que su sufrimiento sirva para algo; que su testimonio fomente la reflexión, para que la gente se dé cuenta de la insensatez del sistema carcelario y cuestione sus prejuicios. No son objetivos sencillos, pero Simone no puede dejarlos de lado. Después de todo, como consecuencia de lo vivido en prisión, ha experimentado cierto devenir activista contra el sistema penitenciario. Más allá de su caso individual, ha sabido hacer una lectura política, pasando de la mera transgresión al cuestionamiento, del discurso implícito al explícito. Desde que dejó la prisión, sus planteamientos han ido transformándose, mostrando una actitud cada vez más crítica con el régimen carcelario, así como una mayor conciencia sobre las discriminaciones que ocurren en su seno. 


\section{DESIGUALDADES, RESISTENCIAS Y AGENCIA EN PRISIÓN}

Tal y como se ha ido anotando en los apartados anteriores, el sistema penitenciario es totalmente androcéntrico y sexista para las mujeres encarceladas, porque (re)produce los roles tradicionales y las relaciones de género jerárquicas, acentuando las desventajas y la vulnerabilidad social de las reclusas (Almeda 2003; Cruells e Igareda 2005; Ballesteros 2017). Del mismo modo, es un sistema que agrava la fragilidad social de las presas de origen extranjero - especialmente, de las que están en situación irregular - (Ribas, Almeda y Bodelón 2005; Imaz y Martín-Palomo 2007), en tanto que todo su entramado está diseñado y preparado para un tipo de sujeto que, además de "hombre", es "nacional", con lo que las reclusas extranjeras quedan en un segundo plano. Yendo aún más allá, también es necesario señalar que el sistema penitenciario es extremadamente selectivo y que según criterios de clase y etnia/raza, solo persigue y castiga la criminalidad de los sectores más pobres y vulnerables (Wacquant 2001; Davis 2003). El carácter sexista, clasista y racista del sistema penitenciario es tan profundo que, a pesar de que muchas de las reclusas extranjeras cuentan con estudios superiores (Juliano 2011: 162), eso nunca llega a ser un elemento que las aleje de la posibilidad de ser encarceladas, porque la división social del trabajo - en base a categorías de estratificación social - hace que ellas solo puedan acceder a los trabajos más desprestigiados y peor pagados (Offenhenden 2017). Ese sería justamente el caso de Simone, que pese a haber realizado estudios universitarios en su país, solo ha podido trabajar en ámbitos de escaso reconocimiento social.

Los centros penitenciarios, por tanto, están colmados de múltiples desigualdades. ${ }^{9}$ Pero, a pesar de ello, Simone asegura no haber tomado conciencia de sus desventajas como "mujer-presa-extranjera" hasta haber salido de la situación de encierro; porque durante su reclusión tenía muchas otras preocupaciones, que le dificultaban poder reflexionar sobre su estado de opresión. En cualquier caso, los archivos guardados en su carpeta aportan datos muy relevantes sobre las citadas desigualdades de género, clase y etnia/raza.

Para empezar, hay toda una serie de discriminaciones penitenciarias que tienen que ver con las comunicaciones exteriores. Algunos autores clásicos (Goffman 2001 [1961]; Foucault 2012 [1975]) ya señalaron que el aislamiento de las personas presas era una de las herramientas utilizadas por el sistema penitenciario para imponer su autoridad y, así, tratar de corregir y disciplinar a las y los presos. Más recientemente, muchas y muchos investigadores (Cunha 1994, 2002, 2008; Maciel 201 1; Cunha y Granja 2014) se han

9 Las desigualdades de género, clase y etnia/raza del sistema penitenciario también han sido señaladas en el ámbito portugués (Cunha 1994, 2002; Cunha y Granja 2014; Gomes 2014; Gomes y Granja 2015). 
decantado por visiones más porosas y dinámicas, según las cuales existen constantes interacciones y articulaciones entre el interior y el exterior de la prisión. Pero incluso desde esas perspectivas que cuestionan la ruptura, interrupción o discontinuidad de los ámbitos, es innegable que, para la institución carcelaria, controlar y obstaculizar los contactos entre el interior y el exterior es de suma importancia. En lo que respecta a la situación concreta de las mujeres encarceladas, los estudios han mostrado que ellas reciben menos visitas y ayudas económicas externas, siendo especialmente crítica la situación de las extranjeras (Almeda 2003; Ribas, Almeda y Bodelón 2005). Muchas, además, tienen dificultades de contacto con su lugar de origen, porque no se tiene en cuenta ni la diferencia horaria, ni el coste mayor de las llamadas al extranjero (Ribas, Almeda y Bodelón 2005: 78).

En la carpeta de Simone, descubrimos varios documentos que reflejan el devenir de sus contactos con el exterior. El primero de ellos es una hoja explicativa sobre las diversas opciones comunicativas autorizadas en prisión. Alguien del personal penitenciario se la entregó el mismo día que fue encarcelada, marcándole con un bolígrafo sus posibilidades: al no tener pareja ni ser madre, los vis a vises "íntimos" y "de convivencia" están tachados; los vis a vises "familiares" - que también podrían ser con amistades - y las comunicaciones orales, a través de locutorio, están marcadas como opciones posibles; pero las llamadas telefónicas están destacadas con un círculo y dos flechas, indicando que son las más adecuadas para el caso de Simone. El resto de archivos de su carpeta, ciertamente, confirman esas primeras impresiones. Por un lado, a través de varias solicitudes para comunicar por locutorio, hallamos que durante su primer mes en prisión recibió las visitas de su abogada, tres amigas y algunas familiares de la mujer mayor que atendía como cuidadora interna. La visitaron una o dos veces, pero luego ya Simone no volvió a saber nada de ellas y nunca tuvo un vis a vis. Por otro lado, la documentación sobre sus contactos telefónicos refleja que ésa fue su principal forma de comunicar con el exterior. Sin embargo, pese a poder completar una lista de hasta diez números de teléfono, ella nunca tuvo más de cuatro o cinco contactos al mismo tiempo y, de entre esos, los únicos que mantuvo durante todo su encierro solo fueron los de sus padres y su hermana en Brasil; algo que muestra claramente que, como ya hemos visto, y al igual que muchas otras presas de origen extranjero, en el País Vasco apenas tenía red social y su único apoyo estable fue el de su familia, desde la distancia. No obstante, es de destacar que la última lista de contactos telefónicos de Simone también es ilustrativa de las prácticas de resistencia de las mujeres encarceladas, ya que entre sus contactos aparecen varias amistades que no son suyas, sino de su compañera de celda, burlando así la norma de no más de diez números de teléfono por reclusa.

Entre la información recopilada por Simone, también encontramos algunos documentos relativos al control, la vigilancia y la disciplina del sistema 
penitenciario. Sin duda, aspectos que suponen los cimientos del encierro como medio de corrección, en su afán por lograr la sumisión y la obediencia de las personas presas, a través de su examen y clasificación, así como a través de una lógica de premios y castigos (Goffman 2001 [1961]; Foucault 2012 [1975]). Aspectos que además son destacables desde una perspectiva de género, ya que diversas investigaciones han señalado que, a partir de concepciones sexistas por parte del funcionariado, con ellas la disciplina y el control son más estrictos y se les exige una mayor docilidad, llegando a ser sancionadas más duramente y frecuentemente que los hombres presos (Aguilera 2011).

Desde ese punto de vista del carácter correctivo de la institución penitenciaria, el primer documento destacable de Simone es su "programa individualizado de tratamiento" (PIT), esto es, el plan de objetivos penitenciarios diseñado por la Junta de Tratamiento para ella, con intención de superar sus "carencias". En dicho programa, las y los profesionales de la prisión destacan su "ausencia de apoyo social", así como sus "necesidades/intereses laborales", fijando como metas "consolidar hábitos laborales", "potenciar la participación en recursos externos" y "potenciar la realización de actividades positivas". En el apartado dedicado a las observaciones, se especifica que "su nivel de cumplimiento/incumplimiento será tenido en cuenta a efectos de recompensas y beneficios penitenciarios, así como en su valoración a la hora de su revisión de grado", porque pese a no ser obligatoria la realización del PIT, su omisión equivale a cumplir la totalidad de la condena en situación de encierro. A sabiendas de ello, Simone optó por llevar a cabo todas las actividades que pudieran proporcionarle una buena imagen ante la Junta de Tratamiento, incluso aunque no fueran tareas concretas de su PIT. La revisión de actividades del PIT que hallamos en su carpeta da buena cuenta de ello, ya que descubrimos que en sus primeros nueve meses en prisión llegó a realizar hasta 27 actividades, recibiendo calificaciones realmente favorables: 15 "excelentes", 8 "destacados" y 4 "normales".

Igualmente, otros documentos del archivador de Simone también nos dan pistas sobre la dinámica de recompensas y castigos que caracteriza al sistema penitenciario. Por una parte, las puntuaciones trimestrales por la participación en ocupaciones del PIT nos permiten conocer qué tareas realizó Simone y cómo fueron valoradas por parte de la Junta de Tratamiento: auxiliar de comedor (9,9 puntos), nivel I de castellano para extranjeros ( 108,0 puntos), experto en limpieza (24,0 puntos), artesanía comercial (24,0 puntos), manualidades (21,0 puntos), etc. Por otra parte, las solicitudes y concesiones de recompensas por participación positiva en actividades nos dan cuenta de los premios ofertados y el coste de cada uno de ellos: comunicación extraordinaria (40 puntos), nota meritoria con efectos cancelatorios de sanciones (30 puntos), nota meritoria sin efectos cancelatorios (25 puntos), permanencia en celda por las tardes (40 puntos), etc. Simone fue decantándose por unos premios u otros, según 
las opciones y necesidades que tenía en cada momento. En cualquier caso, tal y como indican los documentos citados, y relata también la propia Simone, ella fue una "presa ejemplar" para la Junta de Tratamiento - incluso a pesar de recurrir algunas de sus decisiones -. Varios estudios (Bosworth 1999; Ribas, Almeda y Bodelón 2005) han señalado que, a pesar de ser una práctica muy exigente y arriesgada, algunas mujeres reclusas deciden actuar como presas de confianza del funcionariado, pensando que es la opción más favorable para obtener "favores" - no oficiales - y beneficios penitenciarios. Simone afirma que para ella fue como crear un personaje o llevar una máscara; se mostraba sumisa y obediente ante el personal de prisión, pero a sus espaldas no dudaba en referirse a ellas y ellos con apodos despectivos como "Sargento Megera", "Formiga Atômica", "Mata Hari", o "Frango", tal y como hacían también el resto de mujeres encarceladas. En opinión de Simone, si no se tienen apoyos cercanos en el exterior, no quedan muchas más opciones que ser una presa modélica, porque las relaciones de poder entre el personal penitenciario y la población reclusa generan sentimientos de gran soledad y desprotección:

"Ahí... tú tienes claro, desde el primer día, que tú eres un número. [...] iNadie te conoce! iNo son tus padres! iNo son tu círculo social! [...] Es como si tú no existieses. iEres invisible! Todos ahí somos invisibles. Yo creo que las personas tienen más dignidad, cuando tienen más visitas, porque están con los suyos. Pero yo no he tenido esto, porque no tengo nadie aquí, de mi familia ni... No tenía círculo social. Entonces, iyo no era nada! No era considerada nada. [...] iPodían hacer lo que quisiesen conmigo!"

Más allá de los documentos ya mencionados, en la carpeta de Simone hay más archivos que proporcionan información sobre las actividades formativas y laborales que hizo en prisión. Así, a través de algunos certificados y documentos semejantes, pero sobre todo a través de una gran cantidad de instancias enviadas a la Junta de Tratamiento, hallamos que Simone llevó a cabo numerosos cursos y talleres: desarrollo de habilidades sociales, resolución de conflictos, técnicas y búsqueda de empleo, primeros auxilios, limpieza de inmuebles, manipulación de alimentos, bailes, teatro, mandalas (figura 5), etc. Según cuenta, trató de hacer todas las actividades que podía; por una parte, como ya hemos visto, para dar una buena imagen a la Junta de Tratamiento y conseguir puntos; pero, por otra, también para tratar de distraerse de sus preocupaciones y ocupar el tiempo de alguna forma.

Las instancias de Simone, igualmente, nos aportan datos significativos sobre otras dos cuestiones. En primer lugar, es posible observar que ella ha escrito la mayoría de las solicitudes, pero algunas de ellas han sido redactadas total o parcialmente por su compañera de celda; hecho que nos vuelve a remitir a las relaciones de solidaridad y apoyo mutuo creadas entre las mujeres 


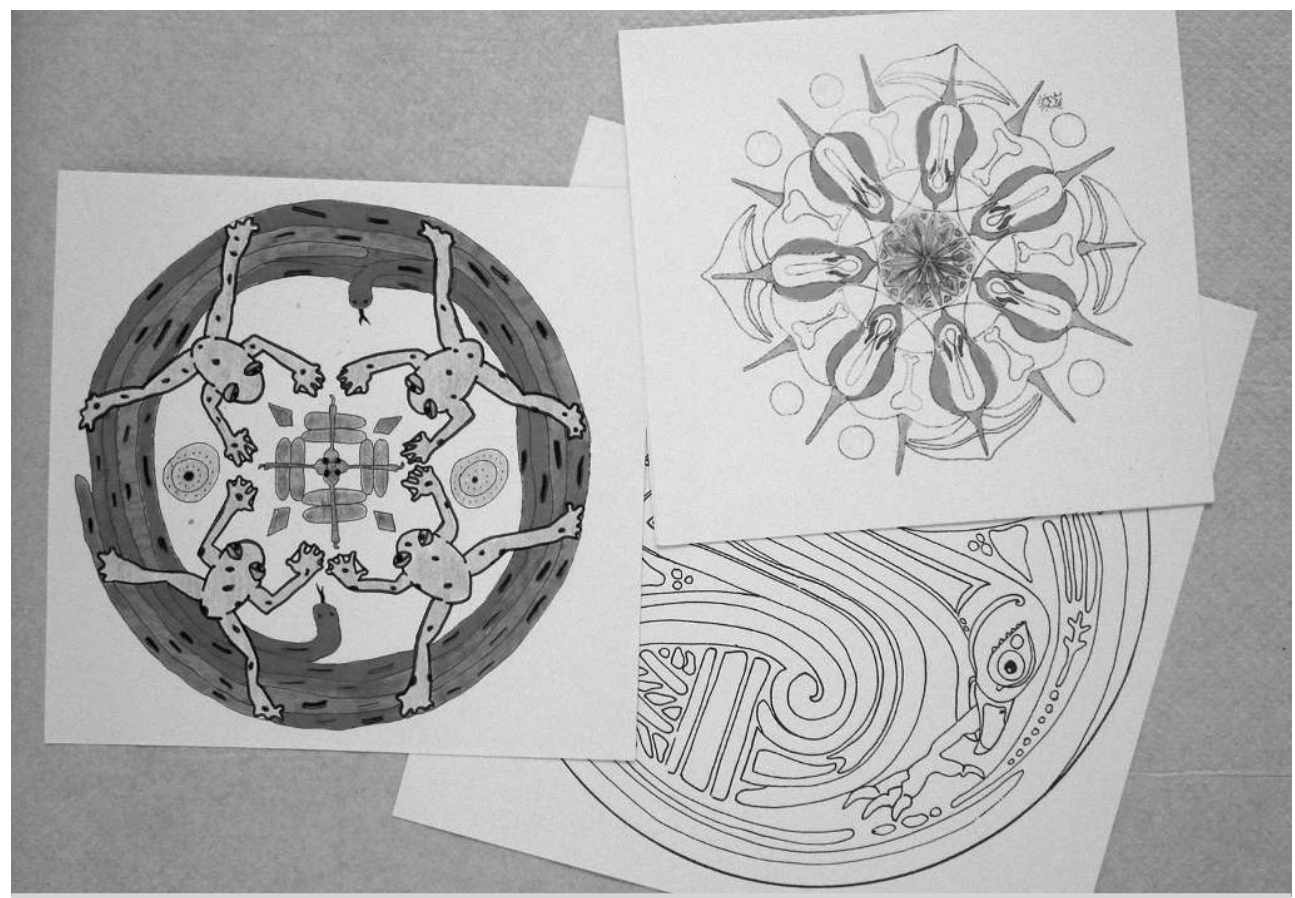

Figura 5 - Mandalas pintados por Simone. Foto: María Ruiz Torrado.

encarceladas. En segundo lugar, es fácil percatarse de que el lenguaje utilizado no es demasiado habitual fuera de los muros penitenciarios; ya que las instancias están repletas de fórmulas que pretenden dejar patente la aceptación de la autoridad del personal carcelario: "estimada señora", "por favor, solicito permiso para participar", "agradezco desde logo la atención dispensada", "a la espera de su respuesta, aprovecho la ocasión para saludarles atentamente", "no aguardo de su resposta, atenciosamente”, etc. El uso de ese tipo de expresiones, que hacía que Simone se viese tan inferior como dependiente, es reflejo del proceso de aprendizaje mencionado anteriormente.

En lo que respecta a las desigualdades relacionadas con las actividades formativas y laborales de prisión, se ha señalado que las mujeres disponen de menos recursos económicos, materiales y personales, teniendo un acceso más limitado a muchos cursos, talleres y espacios, como consecuencia de que la planificación y la gestión penitenciaria se oriente a los hombres, sus necesidades y demandas (SGIP 2009: 4). En el caso de las pocas opciones laborales, se observa que, aunque el número de mujeres con empleo ha ido en aumento, también ha ido incrementándose la brecha de salarios, porque ellas trabajan en las actividades peor remuneradas (Viedma y Frutos 2012: 103), a menudo relacionadas con tareas feminizadas y desprestigiadas. Casi las tres cuartas partes de sus empleos son servicios a la propia red penitenciaria y tareas auxiliares, 
frecuentemente indeterminadas y de escasa especialización (SGIP 2009: 18). Por tanto, son actividades que no sirven demasiado de cara al exterior y, además, suponen una experiencia laboral muy difícil de acreditar, sobre todo para las mujeres extranjeras en situación irregular.

Las nóminas y las notificaciones de altas y bajas laborales guardadas por Simone en su carpeta reflejan claramente la realidad laboral de las mujeres encarceladas "sin papeles". Entre las escasas posibilidades de empleo que había para las mujeres, Simone tuvo la oportunidad de trabajar limpiando los comedores, la sala de los vis a vises y la garita de las funcionarias, como dependienta de economato y en tareas de mantenimiento. Para ella, tener un empleo era deseable de cara a dar una buena imagen a la Junta de Tratamiento, distraerse y ganar algo de dinero, ya que no quería recurrir a la ayuda económica de su familia. En cualquier caso, nunca recibió más de 248,27 euros al mes. Trabajó en el centro penitenciario dada de alta en la Seguridad Social, hasta que le concedieron el régimen abierto y se extinguió su "relación laboral especial"; lo que, como extranjera en situación irregular, significa que el trabajo realizado no consta oficialmente en ninguna parte.

Para terminar con las desigualdades penitenciarias reflejadas en la documentación de la carpeta de Simone, hay que dedicar unas líneas también al estado de salud de las mujeres presas. En lo que a ese tema respecta, los estudios han destacado que los servicios y recursos sanitarios de prisión son inadecuados y que, como consecuencia de ello, ocurre una sobre-medicalización, especialmente grave en el caso de las mujeres, ya que a ellas se les recetan más tranquilizantes, antidepresivos y ansiolíticos (Del Val 2012: 140), como resultado de visiones naturalizadoras y estereotipadas que las presentan como histéricas, inestables, más emocionales e irracionales que los hombres (Almeda 2003; Mountian 2007). Asimismo, las investigaciones han señalado que el encarcelamiento tiene importantes consecuencias a nivel psicológico y físico; siendo, de nuevo, principalmente preocupante la situación de las presas (Del Val 2012; Ruiz Torrado 2016).

Entre los documentos de Simone, encontramos los resultados de varios análisis de orina, realizados sucesivamente en un período de seis meses. Según cuenta, le hicieron un seguimiento especial, con el objeto de saber si se estaba drogando, porque venía sufriendo unos ataques con convulsiones. Después de dar negativo en todos los controles de droga y de pasar por una serie de pruebas médicas, el diagnóstico fue que padecía estrés emocional por el impacto del encierro penitenciario. Al fin y al cabo, para ella era algo tremendamente angustiante y doloroso:

"Agobiante. Es la experiencia más dura que una persona puede pasar. Es te atar, ¿sabes? Es como si estuvieras atada. [...] iNo te dejan salir! Te quitan tus movimientos. [...] Tú estás muy torpe, muy agobiado... [...] No he 
quitado todavía esa sensación de agobio. [...] Parece que hasta el aire es... No es un aire natural. Porque parece que es... [...] Es como una cápsula. [...] Da la sensación que tú estás siempre con una bombona de oxigênio, ¿no? Y que en cualquier momento te va a ir, te va a acabar y tú vas a quedar sin aire. [...] He vivido muchísimo con esa sensación, esa ansiedad... ese estresse".

Critica que, no obstante, la respuesta del centro penitenciario consistió en atiborrarla de ansiolíticos y tranquilizantes.

\section{CONSIDERACIONES FINALES}

Como hemos podido ver, la carpeta de Simone evoca su paso por prisión, conectándola en cada uno de sus encuentros con el espacio penitenciario, el tiempo de encierro y las personas con las que compartió esa parte de su biografía. Sin duda, son ocasiones de gran intensidad, en las que las narraciones y las emociones se recrean, reactualizando los contenidos, dentro de un proceso abierto y dinámico. Desde esa óptica debemos abordar los motivos de Simone para conservar la carpeta durante todos estos años; ya que salta a la vista la importancia que la carpeta posee para ella, en tanto que producto y productora de su vivencia en prisión.

Asimismo, la carpeta remite al carácter discriminatorio del sistema penitenciario, desde una perspectiva de género, clase y etnia/raza. Los documentos archivados permiten indagar en el estigma de las mujeres presas, los sentimientos de culpa y vergüenza hacia la familia, la mayor soledad y vulnerabilidad de las reclusas extranjeras, y, en definitiva, una extensa lista de desigualdades. Paralelamente, la carpeta también posibilita apreciar algunas de las prácticas de resistencia y agencia que las mujeres presas llevan a cabo para tratar de atenuar en su día a día los efectos de la reclusión penitenciaria; prácticas como crear redes de apoyo y solidaridad entre ellas y/o como desarrollar formas de superar las limitaciones comunicativas impuestas por la prisión. 


\section{BIBLIOGRAFÍA}

AGUILERA, Marga, 2011 , "Mujeres presas: la doble condena”, en César Manzanos (comp.), Políticas Sociales para Abolir la Prisión. Vitoria-Gasteiz, Ikusbide, 11 1-120.

ALMEDA, Elisabet, 2003, Mujeres Encarceladas. Barcelona, Ariel.

ALMEDA, Elisabet, 2010, "Privación de libertad y mujeres extranjeras: viejos prejuicios y nuevas desigualdades", en Fanny Añaños (comp.), Las Mujeres en las Prisiones: La Educación Social en Contextos de Riesgo y Conflicto. Barcelona, Gedisa, 201-234.

ALONSO REY, Natalia, 2012, "Las cosas de la maleta: objetos y experiencia migratoria", Arxiu d'Etnografia de Catalunya, 12: 33-56.

ALONSO REY, Natalia, 2016, “De objetos y migraciones: 'hacer las maletas' ", Ankulegi, 20: 31-46.

ALONSO REY, Natalia, 2017, Unas Cuantas Cosas: Objetos Biográficos y Experiencias Migratorias. Tarragona, Universitat Rovira i Virgili, tesis doctoral.

APPADURAI, Arjun (comp.), 1988, The Social Life of Things. Cambridge, UK, Cambridge University Press.

BALLESTEROS, Ana, 2017, "Redomesticidad y encarcelamiento femenino en el sistema penitenciario español”, Papers, 102 (2): 261-285.

BAUDRILlARD, Jean, 2010 [1968], El Sistema de los Objetos. Madrid, Siglo XXI.

BHAVNANI, Kum-Kum, y Angela Y. DAVIS, 2007 [1996], “Mujeres presas, estrategias de transformación”, en Barbara Biglia y Conchi San Martín (comps.), Estado de Wonderbra: Entretejiendo Narraciones Feministas sobre las Violencias de Género. Barcelona, Virus, 197. $-215$.

BOSWORTH, Mary, 1999, Engendering Resistance: Agency and Power in Women's Prisons. Aldershot, Ashgate.

CRUELlS, Marta, y Noelia IGAREDA (comps.), 2005, Mujeres, Integración y Prisión. Barcelona, Aurea.

CUNHA, Manuela P. da, 1994, Malhas que a Reclusão Tece: Questões de Identidade Numa Prisão Feminina. Lisboa, Cadernos do Centro de Estudos Judiciários.

CUNHA, Manuela Ivone Pereira da, 2002, Entre o Bairro e a Prisão: Tráfico e Trajectos. Lisboa, Fim de Século.

CUNHA, Manuela Ivone P. da, 2008, “Closed circuits: kinship, neighborhood and incarceration in urban Portugal”, Ethnography, 9 (3): 325-350.

CUNHA, Manuela P. da, y Rafaela GRANJA, 2014, "Gender asymmetries, parenthood and confinement in two Portuguese prisons", Champ Penal, XI, disponible en $<$ http://champp enal.revues.org/8809 > (última consulta en junio de 2019).

CURCIO, Renato, 2011, "Donde todo comenzó", en Dario Malventi (comp.), Umbrales: Fugas de la Institución Total. Sevilla, UNIA, 14-20.

DAVIS, Angela Y., 2003, Are Prisons Obsolete?. Nueva York, Seven Stories Press.

DAVIS, Nanette, y Karlene FAITH, 2002, “Las mujeres y el Estado: modelos de control social en transformación”, CODHEM, 26: 90-102.

DEL VAL, Consuelo, 2012, "Encierro y derecho de salud", en Consuelo del Val y Antonio Viedma (comps.), Condenadas a la Desigualdad: Sistema de Indicadores de Discriminación Penitenciaria. Barcelona, Icaria, 109-141.

FAITH, Karlene, 2011 [1993], Unruly Women: The Politics of Confinement \& Resistance. Nueva York, Seven Stories Press. 
FILI, Andriani, 2013, "Women in prison: victims or resisters? Representations of agency in women's prisons in Greece”, Signs, 39 (1): 1-26.

FOUCAULT, Michel, 2012 [1975], Vigilar y Castigar. Madrid, Biblioteca Nueva.

GÁNDARA, Lelia, 2005, "Voces en cautiverio: un estudio discursivo del graffiti carcelario", en Antonio Castillo y Verónica Sierra (comps.), Letras Bajo Sospecha. Gijón, Trea, 237 -255 .

GELl, Alfred, 1998, Art and Agency: An Anthropological Theory. Oxford, Clarendon Press.

GOFFMAN, Erving, 2001 [1961], Internados: Ensayos sobre la Situación Social de los Enfermos Mentales. Buenos Aires, Amorrortu.

GOFFMAN, Erving, 2006 [1963], Estigma: La Identidad Deteriorada. Buenos Aires, Amorrortu.

GOMES, Sílvia, 2014, Caminhos para a Prisão: Uma Análise do Fenômeno da Criminalidade Associada a Grupos Estrangeiros e Étnicos em Portugal. Vila Nova de Famalicão, Edições Húmus.

GOMES, Sílvia, y Rafaela GRANJA (comps.), 2015, Mulheres e Crime: Perspetivas sobre Intervenção, Violência e Reclusão. Vila Nova de Famalicão, Edições Húmus.

HENARE, Amira, Martin HOLBRAAD, y Sari WASTELL (comps.), 2007, Thinking through Things: Theorising Artefacts Ethnographically. Londres, Routledge.

HERRERA MORENO, Myriam, 1993, “Mujeres y prisión”, Cuadernos de Política Criminal, 49 : 339-354.

HICKS, Dan, 2010, “The material-cultural turn: event and effect”, en Dan Hicks y Mary Beaudry (comps.), The Oxford Handbook of Material Culture Studies. Oxford, Oxford University Press, 25-98.

IMAZ, Elixabete, y Teresa MARTÍN-PALOMO, 2007, "Las otras otras: extranjeras y gitanas en las cárceles españolas”, en Barbara Biglia y Conchi San Martín (comps.), Estado de Wonderbra: Entretejiendo Narraciones Feministas sobre las Violencias de Género. Barcelona, Virus, 217-227.

JULIANO, Dolores, 2004, Excluidas y Marginales. Madrid, Cátedra.

JULIANO, Dolores, 2009, "Delito y pecado: la transgresión en femenino", Política y Sociedad, 46 (1-2): 79-95.

JUliano, Dolores, 201 1, Presunción de Inocencia: Riesgo, Delito y Pecado en Femenino. DonostiaSan Sebastián, Gakoa.

LATOUR, Bruno, 1993, We Have Never Been Modern. Cambridge, MA, Harvard University Press.

LAVIOLETTE, Patrick, 2013, "Introduction. Storing and storying the serendipity of objects", en Anu Kannike y Patrick Laviolette (comps.), Things in Culture, Culture in Things: Approaches to Culture Theory 3. Tartu, University of Tartu Press, 13-33.

MACIEL, Daniel, 2011, "O trabalho de campo institucional: entrar e sair de um estabelecimento prisional”, en Luis Díaz, Óscar Fernández y Pedro Tomé (comps.), Lugares, Tiempos, Memorias: La Antropología Ibérica en el Siglo XXI. León, Universidad de León, 835-842.

MAGEEHON, Alexandria, 2008, "Caught up in the system: how women who have been incarcerated negotiate power”, The Prison Journal, 88 (4): 473-492.

MAKOWSKI, Sara, 1997, "Formas de resistencia y acción colectiva en cárceles de mujeres", Fermentum, 7 (19): 68-77.

MÉNDEZ, Lourdes, 2008, Antropología Feminista. Madrid, Síntesis.

MILlER, Daniel, 1987, Material Culture and Mass Consumption. Oxford, Basil Blackwell. 
MOUNTIAN, Ilana, 2007, "Mujeres bajo control", en Barbara Biglia y Conchi San Martín (comps.), Estado de Wonderbra: Entretejiendo Narraciones Feministas sobre las Violencias de Género. Barcelona, Virus, 73-82.

NAREDO, María, 2007, "Reclusas con hijos/as en la cárcel”, en Elisabet Almeda y Encarna Bodelón (comps.), Mujeres y Castigo: Un Enfoque Socio-Jurídico y de Género. Madrid, Dykinson, 263-275.

OFFENHENDEN, María, 2017, "Si Hay que Romperse Una, Se Rompe": El Trabajo del Hogary la Reproducción Social Estratificada. Tarragona, Universitat Rovira i Virgili, tesis doctoral.

ORTNER, Sherry B., 2006, Anthropology and Social Theory. Durham, NC, Duke University Press.

RETOLAZA, Iratxe, 2014, “Kartzela-kronikak eta kartografiak: subjektu kartzelatutik kartzela-subjekturantz", en Markel Ormazabal, Hemen Naiz, ez Gelditzeko Baina. Tafalla, Txalaparta, 141-162.

RIBAS, Natalia, Elisabet ALMEDA, y Encarna BODELÓN, 2005, Rastreando lo Invisible: Mujeres Extranjeras en las Cárceles. Barcelona, Anthropos.

RUIZ TORRADO, María, 2016, Kartzela genero-erakunde bezala: genero-bereizkeriak, erresistentzia-praktikak eta agentzia Euskal Herrian espetxeratutako emakumeen artean. Donostia-San Sebastián, Universidad del País Vasco, tesis doctoral.

SGIP - SECRETARÍA GENERAL DE INSTITUCIONES PENITENCIARIAS, 2009, Programa de Acciones para la Igualdad entre Mujeres y Hombres en el Ámbito Penitenciario. Madrid, Ministerio del Interior.

STRATHern, Marilyn, 1999, Property, Substance, and Effect: Anthropological Essays on Persons and Things. Londres, Athlone Press.

THuRÉN, Britt-Marie, 1993, El Poder Generizado: El Desarrollo de la Antropología Feminista. Madrid, Universidad Complutense de Madrid.

VIEDMA, Antonio, y Lola FRUTOS, 2012, "El trabajo en prisión: observando las desigualdades de género", en Consuelo del Val y Antonio Viedma (comps.), Condenadas a la Desigualdad: Sistema de Indicadores de Discriminación Penitenciaria. Barcelona, Icaria, 87-108.

WACQUANT, Loïc, 2001, Las Cárceles de la Miseria. Madrid, Alianza.

WAGNER, Roy, 1986, Symbols that Stand for Themselves. Chicago, The University of Chicago Press. 